\title{
Su Altı Görüntülerinden Nesne Tespiti
}

\author{
Ekrem Eşref Kılınç ${ }^{1 *}$, Sedat Metlek ${ }^{2}$ \\ ${ }^{1}$ Burdur Mehmet Akif Ersoy Üniversitesi, Ağlasun Meslek Yüksekokulu, Bilgisayar Teknolojisi ve Programlama Bölümü, Burdur, Türkiye, \\ (ORCID: 0000-0003-1806-4937), ekilinc@mehmetakif.edu.tr \\ ${ }^{2}$ Burdur Mehmet Akif Ersoy Üniversitesi, Teknik Bilimler Meslek Yüksekokulu, Kontrol ve Otomasyon Bölümü, Burdur, Türkiye, \\ (ORCID: 0000-0002-0393-9908), sedatmetlek@ mehmetakif.edu.tr
}

(İlk Geliş Tarihi 3 Şubat 2021 ve Kabul Tarihi 4 Nisan 2021)

(DOI: 10.31590/ejosat.873540)

ATIF/REFERENCE: Kılınç, E. E. \& Metlek, S. (2021). Su Altı Görüntülerinden Nesne Tespiti. Avrupa Bilim ve Teknoloji Dergisi, (23), 368-375.

\section{$\ddot{\mathrm{O} z}$}

Yeryüzünün büyük bir kısmı sularla kaplıdır. Bu suların büyük bir çoğunluğunu da okyanuslar oluşturmaktadır. Bu kadar çok alanın sularla kaplı olmasına rağmen sualtı görüntüleme ilgili yapılan araştırmalar, yer üstü araştırmaları kadar çok değildir. Su altı araştırmaları ile ilgilenen araştırmacıların yeterli düzeyde görüntüleme yapabilmeleri için kullanmış oldukları görüntüleme cihazları son derece özel ve maliyetli cihazlardır. Bu cihazlarında özellikle maliyetli olması sualtı görüntülemesi ile ilgilinen araştırmacılar için önemli bir engel oluşturmaktadır. Bu nedenle yapılan çalışmada bu durum göz önüne alınarak düşük kapasiteye sahip donanım ve ekipmanlar kullanılarak elde edilen sualtı görüntüleri üzerinden nesne tespit edilmesi amaçlanmıştır. Bu amaç doğrultusunda AQUALOC veri setinde ki düşük çözünürlüklü sualtı görüntüleri ve görüntü işleme algoritmaları kullanılarak, görüntüden nesne tespit işlemi gerçekleştirilmiş̧ir. Çalışma sonunda su altı görüntüleri üzerinden nesne tespiti yapabilecek masaüstü bir yazılım geliştirilmiş olup, tespit ettiği nesnelerin görüntüleri de çalışmada sunulmuştur. Geliştirilen yazılımda minimum hata değerleri olarak MSE, RMSE, MAE ve MAPE hata fonksiyonları için sırasıyla $0.08,0.09,0.28$ ve $\% 16$ olarak elde edilmiştir. Çalışmanın gerçek zamanlı alınabilecek görüntüler üzerinde de uygulanabilir nitelikte olması sualtı araştırmaları ile ilgilenen araştırmacılar içinde oldukça önem arz etmektedir. Bununla birlikte çalışma deniz tabanından geçirilen petrol boru hattı gibi enerji hatları ile diğer iletişim hatlarının güvenliklerini sağlamak amacıyla kullanılan insansız sualtı araçlarında da kullanılabilecektir. Çalışma bu yönü ile de önümüzdeki dönemlerde de geliştirilebilecek bir yapıya sahiptir.

Anahtar Kelimeler: Görüntü işleme, nesne tespiti, sualtı görüntüleme

\section{Object Detectıon From Underwater Images}

\begin{abstract}
A large part of the earth is covered with water. Oceans constitute the majority of these waters. Despite the fact that so many areas are covered with water, research on underwater imaging is not as much as aboveground research. Imaging devices used by researchers interested in underwater research to make adequate imaging are extremely special and costly devices. The high cost of these devices poses an important obstacle for researchers interested in underwater imaging. For this reason, taking this situation into consideration, the study aimed to detect objects through underwater images obtained by using low-capacity hardware and equipment. For this purpose, using the low-resolution underwater images and image processing algorithms in the AQUALOC data set, the object detection process from the image was performed. At the end of the study, a desktop software that can detect objects through underwater images was developed, and the images of the detected objects were also presented in the study. In the developed software, the minimum error values were obtained as 0.08, 0.09, 0.28 and 16\% for MSE, RMSE, MAE and MAPE error functions, respectively. The applicability of the study to real-time images is very important for researchers interested in underwater research. It can also be used in unmanned underwater vehicles used to secure other communication lines such as power lines and oil pipelines that cross the seabed. With this aspect, the study has a structure that can be developed in the future.
\end{abstract}

Keywords: Image processing, object detection, underwater viewing.

*Sorumlu Yazar: ekilinc@ mehmetakif.edu.tr 


\section{Giriş}

Dünyanın yaklaşık olarak \%70’i sularla kaplıdır. İnsanlar için su altındaki geniş biyolojik kaynakların ve su altındaki yaşamın keşfi her zaman dikkat çeken bir konu olmaktadır. Bunun için üzerinde farklı sensörlerin kullanıldığı birçok insanlı ya da insansız sualtı aracı geliştirilmiştir (Nyrkov et al., 2017). $\mathrm{Su}$ altı araçlarından görüntüler elde edilerek, su altı kaynaklarının keşfi, hedef konumlandırması ve tanımlama, navigasyon ve yol planlanması, engellerden kaçınma, boru hatları, haritalama gibi birçok işlemin yapılması sağlanmıştır. Geliştirilen araçlarda sualtı görüntülerinin elde edilmesi ve işlenmesi için kullanılan ekipman ve sensörlerin pahalı olması, yapılan çalışmaların ilerlemesinin önündeki en büyük engel olarak karşımıza çıkmaktadır.

Su altı görüntülerinin elde edilmesi için iki yöntem yaygın olarak kullanılmaktadır. Bunlar çeşitli akustik sensörlerin kullanıldı ̆̆ 1 sonar sistemler ve optik sensörlerin kullanıldı $\breve{g}_{1}$ kamera sistemleridir.

Yunus balıklarının iletişim ve yarasalarında yön bulmada kullandığı Sonar, ingilizce "Sound Navigation and Ranging" ifadesinin kısaltmasıdır. Ses dalgalarının su altında ki yayılma özelliğinden faydalanılarak geliştirilen hem su altında hem de su üstünde gezinmeyi, mesafe aralığını hesaplamayı, haberleşmeyi ve diğer cisimler hakkında bilgi edinmeyi sağlayan teknik bir yöntemdir (Au, 1993). Balık sürülerinin tespitinde, hedeflerin tespit edilmesi ve sinıflandırılmasında, deniz tabanı haritalanmasında, mayın tespitinde genellikle sonar sistemler kullanılır. Sonar sistemlerde kullanılan akustik sensörlerden elde edilen örüntülerde çevresel gürültülerden dolayı hedeflerin, nesnelerin ve engellerin tespitinde zorluklar yaşanmaktadır.

Optik sensörlerin kullanıldığı kamera sistemleri su altı görüntülerinin elde edilmesinde son yıllarda büyük aşama kat etmiştir. Farklı fiyat ve ölçekte birçok farklı kamera çeşidi bulunmaktadır. Kameralar ile çok yüksek çözünürlükte görüntüler elde edilebilir. Fakat bunun yanı sıra sualtında homojen olmayan ışıklandırma, düşük karşıtlık, bulanıklık, deniz karı gibi birçok bozucu etkenden dolayı elde edilen görüntü ile işlem yapmak zor bir hale gelmektedir. Bunun için görüntü iyileştirme algoritmalarından yararlanılarak görüntüdeki problemler en aza indirilmeye çalışılmaktadır (Taşyapı Çelebi, 2012).

Literatürde su altından elde edilmiş görüntülerin; elde edilmesi, işlenmesi ve su altı görüntülerden nesne tespiti ile ilgili hem sonar sistemler hem de kamera sistemleri ile gerçekleştirilmiş bazı önemli çalışmalar da bulunmaktadır.

Literatürdeki çalışmalar genel olarak incelendiğinde alınan görüntülerin nasıl temin edildiğinin önemi bir adım daha öne çıkmaktadır. Bu nedenle su altı görüntüleri ile ilgili yapılacak çalışmalarda, ilk olarak görüntünün nasıl temin edileceği üzerinde detaylı analizler yapmak gerekmektedir (Nur et al., 2020).

Genellikle su altı görüntüleri elde etmek için kullanılan sonar ekipmanlar, spesifik olmasına rağmen çeşitli nedenlerle düşük kalitede görüntüler sunmaktadır. $\mathrm{Bu}$ nedenle de elde edilen görüntüler üzerinde iyileştirmelerin yapılması gerekmektedir. Aynı durum optik lensli sistemler ile elde edilen su altı görüntüleri içinde geçerlidir. Özellikle düşük maliyetli optik lens kullanan ve düşük kalitede görüntü elde edilen sistemlerde de iyileştirmenin yapılması elzemdir. Konu ile ilgili litaratüre bakıldığında optik kameralı sistemlerden elde edilen su altı görüntülerinin iyileştirilmesi için kullanılan yöntemlerden birisinin Ampirik Mod Ayrıştırma (AMD) yönteminin olduğu görülmektedir. $\mathrm{Bu}$ yöntem ile elde edilen görüntülerde dikkat çekici bir başarı elde edilmiştir (Çelebi \& Ertürk, 2012).

$\mathrm{Su}$ altı görüntülerini iyileştirmek için sonar sistemler ile optik kameralı sistemlerin birlikte kullanıldığı çalışmalarda bulunmaktadır. Her iki sistemden elde edilen görüntülerin birleştirilmesi sonucunda görüntü iyileştirmede başarı sağlanabilmiştir (Leblebicioğlu et al., 2015).

$\mathrm{Su}$ altı görüntülerinde insan yapımı nesnelerin tespiti için belirginlik tabanlı bölge birleştirme algoritmaları gibi farklı algoritmalarda geliştirilmiş ve test edilmiştir (Williams \& Groen, 2011), (Zhu et al., 2016).

Mevcut çalışmalarda sualtı nesne tespiti için yaygın olarak renk ve yoğunluk gibi görsel özellikler kullanılmaktadır. Bu özelliklere ek olarak nesne tespitinde 1 şı aktarım bilgilerinin de kullanıldığı çalışmalar bulunmaktadır (Chen et al., 2017).

$\mathrm{Su}$ altından elde edilen görüntülerde çok daha etkin nesne tespiti için günümüzde makine öğrenme yöntemlerinden de yararlanılmaktadır. Nesne tespiti için sonar ile elde edilen görüntüler üzerinde Makine Öğrenme algoritmalarına dayanan uygulamalar da geliştirilmiştir (Karimanzira et al., 2020). Buna ek olarak su altındaki deniz çanlılarının tespiti için de CNN tabanlı (Convolutional Neural Network) yöntemlerde geliştirilmiştir (Han et al., 2020).

Literatürdeki çalışmaların büyük çoğunluğunda, kullanılan görüntüleme ekipmanları oldukça yüksek maliyete sahiptir. Özellikle su altı araştırmalarında bu durum, görüntü işleme uygulamalarının geliştirilmesinin önündeki en büyük engellerden birisidir. $\mathrm{Bu}$ nedenle geliştirilen uygulamada özellikle düşük maliyetli görüntüleme aygıtlarından elde edilen görüntüler tercih edilmiştir.

Çalışmanın ana konusu su altı görüntülerinden cisim tespitinin yapılmasıdır. Burada bahsedilen cisim kavramı, deniz tabanından farklıklık gösteren tüm nesneleri kapsamaktadır. Özellikle çalışmanın bu yönünün, günümüz su altı araştırmacılarının ilgisini çekeceği aşikardır. Buna ek olarak geliştirilen uygulama ile özellikle su altındaki enerji nakil hatlarının çevresinde oluşabilecek anormal durumlarında tespit edilmesi sağlanabilir.

Günümüzde insansız hava araçlarında kullanılan benzer görüntüleme yöntemlerinin sualtı cihazılarında da kullanılması konusuna 1şık tutatacaktır. Bu nedenle çalışma güvenlik amaçlı uygulamalarda da kullanılabilir niteliktedir.

Çalışmanın genel sunum şeklinde, 2. Bölümde kullanılan materyal ve metod anlatılmıştır. 3. Bölümde elde edilen deneysel sonuçlar sunulmuş olup 4.Bölümde çalışmanın sonucu aktarılmıştır. 


\section{Materyal ve Metot}

\subsection{Materyal}

Çalışmada deniz tabanına yakın seyreden su altı araçları için eşzamanlı yerelleştirme ve haritalama yöntemlerinin geliştirilmesi için oluşturulan AQUALOC isimli özel bir veri seti kullanılmıştır (Ferrera et al., 2019). Bu veri seti üç farklı ortamdan kaydedilen verilerden oluşmaktadır.

Kaydedilen verilerin ilki, bir limanın birkaç metre derinliğinden, ikincisi 270 metre derinliğindeki bir arkeolojik siteden ve üçüncüsü ise 380 metre derinliğindeki bir başka arkeolojik siteden elde edilmiştr. Bahsedilen ortamlardan verileri toplamak için, içerisinde monoküler monokromatik kamera, düşük maliyetli eylemsizlik ölçüm ünitesi, basınç sensörü ve bilgi işlem ünitesi bulunan uzaktan kumandalı bir su altı aracı kullanılmıştır.

$\mathrm{Su}$ altı aracının içerisinde bulunan sensörlerden elde edilen ölçüm değerleri, eşzamanlı olarak bilgi işlem ünitesinde hesaplanarak kayıt altına alınmaktadır. Bu kayıt altına alınan veriler on yedi bölümden oluşmakta ve hem BAG (Bathymetric Attributed Grid) dosyası hemde ham veri olarak tutulmaktadır. BAG dosyası batimetrik verileri depolamak ve değiştirmek için geliştirilmiş özel bir dosya formatıdır (Stanford Artificial Intelligence Laboratory et al., 2020).

Kullanılan veri setinde üç ayrı ortamdan elde edilen ham verilerin örnek bir tanesi Şekil 1'de sunulmuştur. Yapılan çalışmanın görüntü tabanlı olması nedeniyle BAG dosyasındaki diğer veriler kullanılmamıştır. Bu nedenle çalışmada Şekil 1'de gösterilen ham veriler tercih edilmiştir.

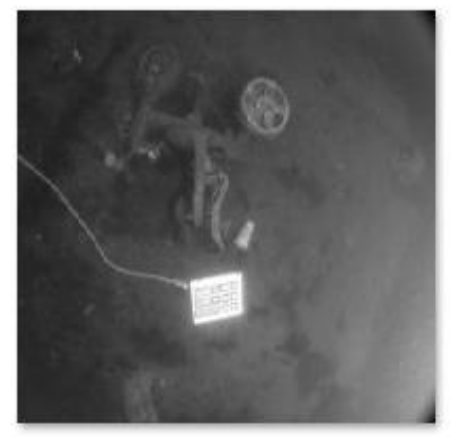

Şekil 1: Ham görüntü verisi

\subsection{Metot}

$\mathrm{Su}$ altı görüntülerinde bulunan nesnelerin tespitine yönelik yapılan çalışmada üç aşamalı bir yöntem kullanılmıştır. Kullanılan yönteme ait aşamalar Şekil 2'de sunulmaktadır.

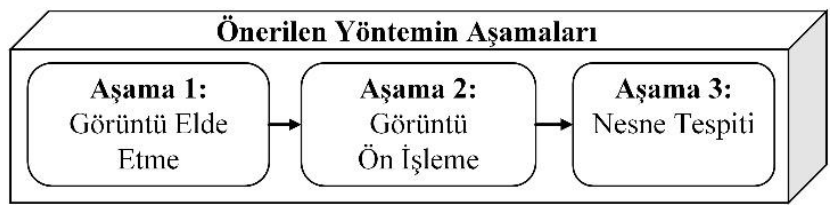

Şekil 2: Önerilen yöntemin aşamaları
Aşama 1'de su altı görüntüleri optik kameralar ile elde edilmiştir. Elde edilen görüntüler AQUALOC veri setine kaydedilmiştir. Çalışmada da bu veri setinde bulunan su altı görüntüleri kullanılmıştır. 1. aşamada veri setinde bulunan dosyaların okunma ve standart değerlere getirme işlemleri gerçekleştirilmiştir.

Aşama 2'de görüntü içindeki mevcut nesnelerin deniz tabanından ayrıştırılıp, daha belirgin ve kolay işlenebilir hale getirilmesi sağlanmıştır.

Son aşamada ise görüntü üzerindeki tüm nesneler tespit edilip, görüntü üzerinde kapladığı değerler belirlenen eşik değerin altında olan nesneler eliminize edilmiştir. Böylece görüntü üzerinde oluşabilecek küçük gürültülerin önüne geçilmesi sağlanmıştır.

Son olarak da görüntü üzerinde tespit edilen nesneler büyüklüğüne göre ekranda gösterilmiştir.

\subsubsection{Görüntü Elde Etme}

İlk aşama olan görüntü elde etme ile veri setine kaydedilmiş olan görüntülerin işlenme aşamasına hazır hale getirilmesi sağlanmıştır.

Optik kameradan elde edilen görüntüler genelde iki farklı görüntü formatında oluşturulmaktadır. Bunlar RGB görüntü formatı ve Gri Tonlamalı (Gray Scale) görüntü formatıdır. RGB'de, görüntüyü oluşturan her bir pixel 0 ile 255 arası değerler alabilen Kırmızı (Red), Yeşil (Green) ve Mavi (Blue) renk değerleri ile temsil edilir. Gri tonlama, RGB renk uzayındaki görüntülerden elde edilen 0 ile 255 arasındaki değerlerden oluşmaktadır. Çalışmada kullanılılan kameralar monokrom kamera olması nedeniyle sistemden elde edilen görüntüler gri tonlama görüntü formatındadır. $\mathrm{Bu}$ nedenle algoritmada kullanılan görüntülerde RBG renk uzayından gri tonlamalı renk uzayına herhangi bir dönüşüm yapılmasına gerek kalmamıştır.

Çalışmada kullanılan veri setindeki görüntü dosyaları 640x512 piksel boyutunda ve 8 bit derinliğindedir. Bu sebeple görüntü dosyasından elde edilen her bir görüntü verisi 640x512 boyutunda bir IG matrisinde saklanarak işleme hazır hale getirilmiştir.

\subsubsection{Görüntü Ön İşleme}

Görüntü ön işleme aşamasında görüntü üzerindeki nesnelerin daha belirgin olması ve kolay tespit edilebilmesi için 3 aşamadan oluşan işlemler sırasıyla uygulanmıştır.

İlk olarak deniz altından elde edilmiş görüntülerde bulunan nesnelerin tespiti için filtre uygulanarak nesnelerin deniz tabanından ayrıştırılması işlemi gerçekleştirilmiştir. İkinci adımda nesnelerin daha belirgin hale getirilmesi sağlanmış ve son adımda ikili görüntü dosya formatına çevirme işlemi yapılmıştır. Şekil 3 'te uygulanan adımlar sunulmaktadır 


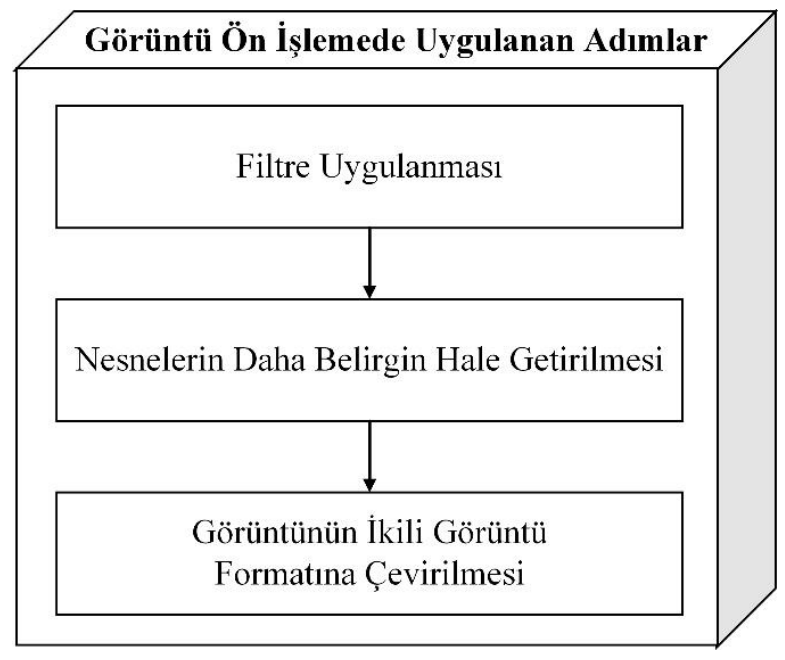

Şekil 3: Görüntü ön işlemede uygulanan adımlar

\section{Filtre uygulanması:}

Görüntüdeki nesnelerin deniz tabanından ayrıştırılması için ilk olarak görüntünün arka plan aydınlanmasının elde edilmesi gerekmektedir. Bunun için görüntü üzerinde morfolojik işlemler uygulanmaktadır. Çalışmada sırasıyla önce aşındırma(erosion) ve sonrada genişleme(dilation) morfolojik işlemleri uygulanmıştır.

Aşındırma işlemi, birbirlerine ince bir gürültü (zayıf bir komşuluk ilişkisi) ile bağlanmış nesnelerin birbirinden ayrılmasını sağlar. Aşındırma görüntüdeki gri alanların daraltılmasını ve siyah bölgede kalan küçük gri alanların temizlenmesini sağlar. Genişleme ise görüntedeki bir nesnenin ince bir gürültü ile bölünerek farklı bir nesne gibi algılanmasını engeller. Genişleme görüntedeki gri alanların genişlemesini sağlarken, gri bölgede kalan siyah noktaları da temizler (Solak \& Altınışık, 2018).

Morfolojik işlemlerin yapılabilmesi için öncelikle $1<\mathrm{N}<\infty$, $\mathrm{NxN}$ boyutunda morfolojik yapısal eleman adı ile ifade edilen matris oluşturulmaktadır. Oluşturulan yapısal eleman görüntü üzerinde dolaştırılır. Dolaştırma işlemi yapılırken uygulanmak istenen morfolojik işlemin tanımına göre görüntüde ki piksel değerleri ile yapısal elemanın değerleri karşılaştırılarak sonuç görüntüsü elde edilir. Farklı uygulamalar için kullanılan, yapısal eleman matrisleri bulunmaktadır. Çalışmada literatürde en çok tercih edilen ve Şekil 4'te gösterilen dairesel morfolojik yapısal eleman kullanılmıştır.

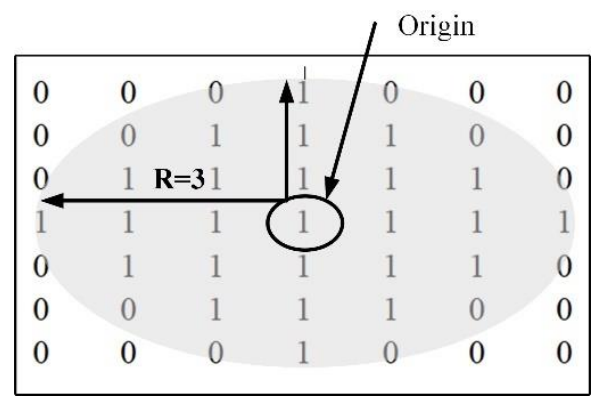

Şekil 4: Dairesel morfolojik yapısal eleman
Morfolojik işlemde giriş verisi olarak belirlenen görüntü üzerinde, yapısal eleman matrisi gezdirilmektedir. Yapısal eleman ve gri tonlamalı görüntü değerlerindeki komşu piksel değerleri yardımı ile aşınma ve genişleme işlemleri uygulanmaktadır.

Denklem 1' de aşındırma ve Denklem 2' genişleme morfolojik işlemlerinin matematiksel olarak gösterimleri sunulmuştur. Denklemlerde $I_{G}$ mevcut gri tonlamalı görüntü matrisini, $I_{M A}$ aşındırma morfolojik işlemi uygulanmış gri tonlamalı görüntü matrisini, $I_{M G}$ genişleme morfoljik işlemi uygulanmış görüntü matrisini, Y ise dairesel yapısal elemana ait matrisi ifade etmektedir (Van Den Boomgaard \& Van Balen, 1992).

$$
\begin{gathered}
I_{M A}(x, y)=I(x, y) \ominus Y(j, z) \Rightarrow \\
\operatorname{Min}_{j, z}[I(x+j, y+z)+Y(j, z)] \\
I_{M G}(x, y)=I_{G}(x, y) \oplus Y(j, z) \Rightarrow \\
\operatorname{Max}_{j, z}\left[I_{G}(x+j, y+z)+Y(j, z)\right]
\end{gathered}
$$

Görüntüye sırasıyla Denklem 1'de gösterilen aşındırma işlemi ve Denklem 2'de gösterilen genişleme işlemi uygulanmıştır. Bu işlem neticesinde elde edilen görüntüde birçok özellik genelleştirilerek arka plana eş değer hale getirilmiştir. Böylece görüntü üzerindeki farklı aydınlanma seviyeleri de eliminize edilmeye çalışılarak arka plan görüntüsü oluşturulmuştur.

Denklem 3' de matematiksel ifadesi sunulan, $I_{G}$ görüntü matrisinden, morfolojik işlemlerin sırası ile uygulanması ile elde edilen arka plan görüntü matrisi çıkarılarak nesnelerin deniz tabanından ayrıştırılması gerçekleştirilmiş olur. Denklem 3' te kullanılan $I_{G G}$ ifadesi en son elde edilen görüntü matrisini ifade etmektedir.

$$
I_{G G}=I_{G}-I_{M G}
$$

\section{Nesnelerin belirgin hale getirilmesi;}

Şekil 5'de gösterilen $I_{G G}$ görüntüsünde Denklem 4 kullanılarak görüntü üzerindeki zıtlıklar ön plana çıkartılmıştır.

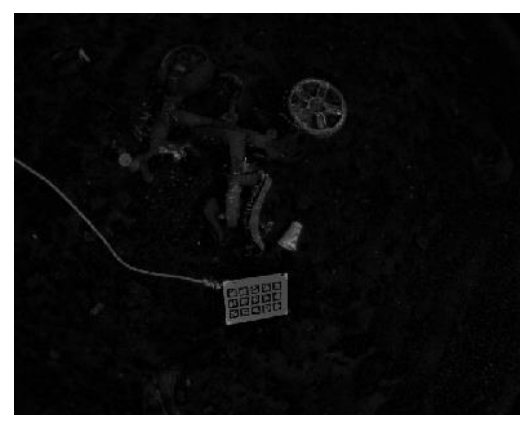

Şekil 5: $I_{G G}$ görüntüsü

$$
I_{G Y}(x, y)=\frac{I_{G G}(x, y)-I_{G G}(x, y)_{\min }}{I_{G G}(x, y)_{\max }-I_{G G}(x, y)_{\min }}
$$


Denklem de kullanılan $I_{G G}(x, y)_{\max }$ görüntüdeki maksimum piksel yoğunluğunu, $I_{G G}(x, y)_{\min }$ görüntüdeki minimum piksel yoğunluğunu, $I_{G Y}(x, y)$ yeni elde edilen piksel değerini, $I_{G G}(x, y)$ zitllğı değiştirilecek piksel değerini ifade etmektedir. $\mathrm{Bu}$ işlem sonucunda Şekil $6^{\prime}$ gösterilen $I_{G Y}$ görüntüsü elde edilmiştir.

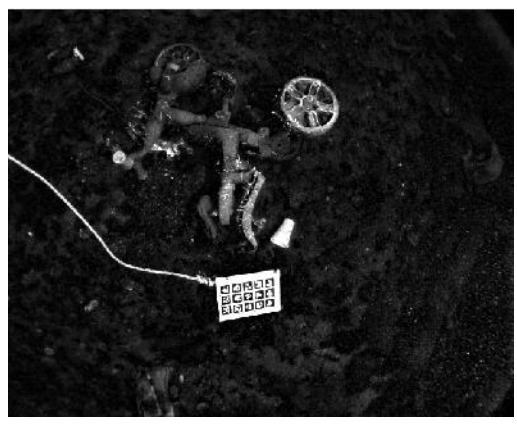

Şekil 6: $I_{G Y}$ görüntüsü

\section{Görüntünün ikili formata çevrilmesi:}

Görüntü ön işlemenin son adımı görüntünün ikili görüntü formatına dönüştürülmesidir. Bir gri tonlamalı görüntüyü ikili görüntü formatına çevirmek için bir eşik değeri belirlenir. Belirlenen eşik değerin üzerindeki değerler 255'e çevrilir. Böylece görüntünün ilgili yerleri beyaza dönüştürülür. Aynı işlem eşik değerin altında kalan değerler içinde benzer şekilde yapılmaktadır. Burada tek fark eşik değerin altındaki değerler 0 'a çevirilir. Bu durumda da ilgili yerler siyaha dönüştürülmüş olur.

Denklem 5' te bu işlem için kullanılan fonksiyon gösterilmiştir. Denklemde kullanılan E ifadesi, eşik değerini göstermektedir.

$$
I_{G}(x, y)=\left\{\begin{array}{cc}
255 & \leftarrow I_{G}(x, y) \geq E \\
0 & \leftarrow I_{G}(x, y) \leq E
\end{array}\right\}
$$

Veri setinden elde edilen ham bir görüntü Şekil $7^{\prime}$ de gösterilmiştir. Çalışmada kullanılan görüntü ön işleme adımlarından sonra elde edilen görüntü Şekil 8'de gösterilmektedir.

Şekil 7 ve 8'de ki farktan da anlaşılacağı üzere, kullanılan görüntü işleme adımlarından sonra görüntü üzerindeki ayrıntılar daha belirgin hale gelerek deniz tabanından ayırt edilebilecek düzeye gelmiştir.

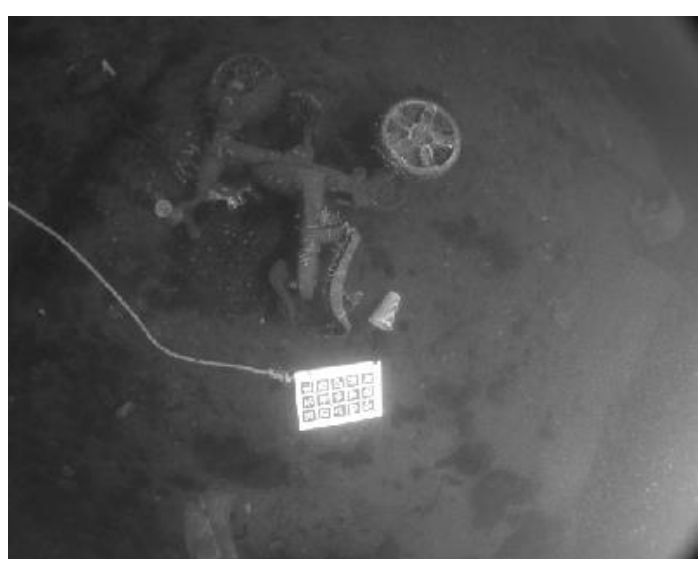

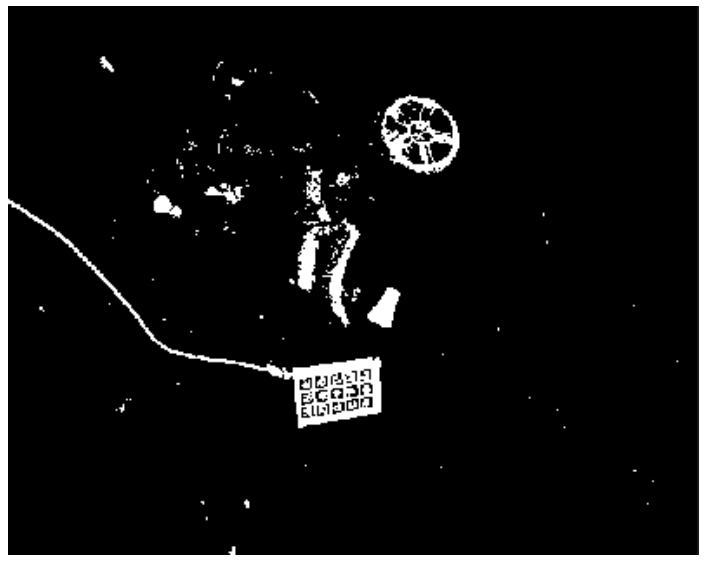

Şekil 8: Görüntü ön işlemesi yapıldıktan sonra oluşan görüntü

\subsubsection{Nesne Tespiti}

Nesne tespit işleminde, görüntü ön işleme adımlarından sonra ikilik formata dönüştürülen görüntü kullanılmıştır. Literatürde benzer görüntüler üzerinde nesne tespit etmek için geliştirilen bazı algoritmalar bulunmaktadır. $\mathrm{Bu}$ algoritmaların genelinde ilk olarak nesnelerin ana hatlarının belirlenmesi sağlanmaktadır.

Gerçekleştirilen çalışmada Suzuki ve Abe tarafından geliştirilen topolojik yapısal analiz işlemi gerçekleştirilerek görüntüdeki nesnelerin sınırları tespit edilmiştir (Suzuki \& be, 1985).

Bu algoritmada öncelikle görüntüdeki ana hatlar(sınırlar), komşu pikseller arasındaki ilişkilere bakılarak belirlenmekte, sonrasında topolojik sıra ile etiketlenmektedir. Algortimanın adı da bu işlemden gelmektedir.

Elde edilen nesneler içerisinde anlamlı ya da anlamsız farklı boyutlarda nesneler bulunmaktadır. Nesnelerin anlamlandırılması ve belli nesnelerin gösterilmesi için etiketlenen her bir nesnenin görüntü üzerinde kapladığı alan hesaplanmaktadır. Denklem 6' da sunulan genel moment alma formülü kullanılarak nesnelerin alanları hesaplanmıştır (Mukundan \& Ramakrishnan, 1998).

$$
\Phi_{p q}=\int_{x} \int_{y} x^{p} y^{p} I(x, y) d x d y \quad p, q=1,2,3 \ldots
$$

Denklem 6'da kullanılan $\mathrm{x}$ ve y değerleri ikili görüntüyü oluşturan matristeki satır ve sütunları, $\Phi_{p q}$ momenti, $I(x, y)$ ikili görüntüyü, $\mathrm{p}$ ve q değerleri ise momentin derecesini ifade etmektedir.

Denklemde momentum dereceleri $p=0$ ve $q=0$ olarak verildiğinde, nesnenin piksel cinsinden alanı $\Phi_{00}$ elde edilmektedir. Uygun moment dereceleri kullanılarak görüntüdeki bütün nesnelerin alanları hesaplanmıştır.

Son aşamada, görüntüdeki parazit ya da istenilmeyen küçük nesnelerin eliminize edilmek istenmesinden dolayı görüntüdeki nesnelerin kapladığı alan bakımından değerleri büyükten küçüğe sıralanmış ve özellikle görüntüde en büyük alana sahip ilk on nesne tespit edilmiştir. Bu durumda Şekil 9'da gösterilmektedir.

Şekil 7: Görüntü ön işleme yapılmamış ham görüntü 


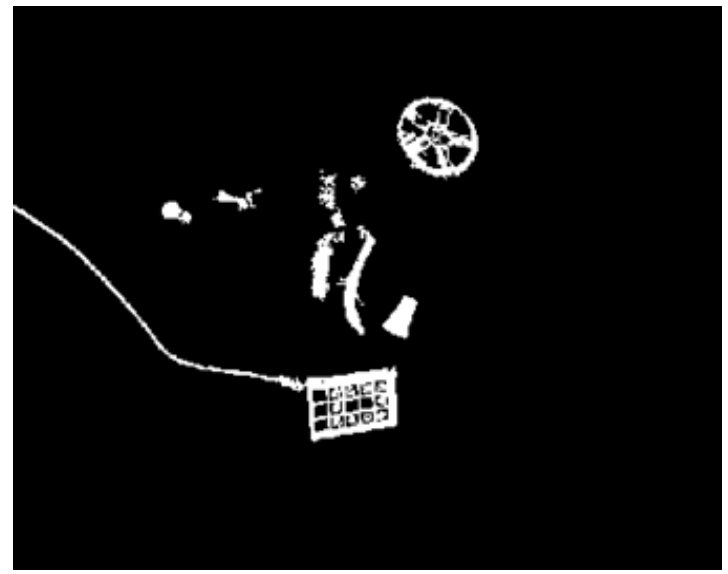

Şekil 9: Görüntüdeki tespit edilen nesneler

\section{Araştırma Sonuçları ve Tartışma}

Geliştirilen uygulamada AQUALOC veri setinde bulunan 640x512 çözünürlüğe sahip görüntüler kullanılmıştır. $\mathrm{Bu}$ görüntüler UEye - UI-1240S sensörlü, 640x512 çözünürlüğe sahip monokromatik bir kamera ile elde edilmiştir. Çalışmada Intel i7 10750H 2.6GHz işlemci, 64GB Ram ve Nvidia GeForce GTX 1650 Tİ ekran kartı donanıma sahip bir bilgisayar kullanılmıştır. Geliştirilen algoritma Matlab ortamında hazırlanmış olup, Image Processing ToolBox kütüphanesinden de yararlanılmıştır. Geliştirilen uygulama görüntü elde etme, ön işleme ve nesne tespit olmak üzere üç temel adımdan oluşmaktadır. $\mathrm{Bu}$ temel adımların her biri geliştirilen arayüz üzerinde senkron bir şekilde çalışmaktadır.

Çalışmada hazırlanan arayüz iki temel menüden oluşmaktadır. Şekil 10'da genel olarak gösterilen ilk menüde veri tabanından alınan ham görüntü ve bu görüntülere ait temel adımlar gösterilmektedir. Şekil 10 (a)'da sistemden alınan ham görüntü, Şekil 10 (b)'de tekrar oluşturulan arkaplan görüntüsü, Şekil 10 (c)'de ham görüntü üzerindeki nesneler, Şekil 10 (d)' de zıtlık artırma işleminden sonra elde edilen görüntü, Şekil 10 (e)' de ikili formata çevrilmiş görüntü, Şekil 10 (f)'de ise parazit ve küçük nesnelerin eliminize edildiği görüntü gösterilmektedir. (a)

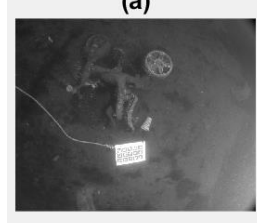

(d)

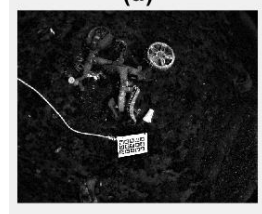

(b)

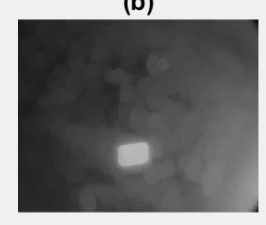

(e)

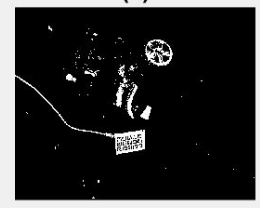

(c)

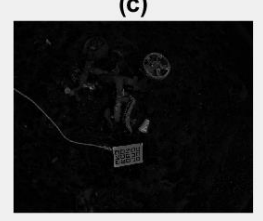

(f)

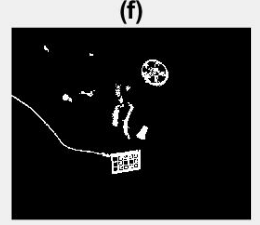

Şekil 10: Menu 1: Nesne tespitinin temel aşamaları

Şekil 11'de gösterilen diğer menüde ise sistemin genel çalışma ara yüzü bulunmaktadır. Bu menüden görüntüler sırayla otomatik geçirilmekte, durdurulmakta, ileri, geri alınabilmektedir. Şekill 11(a)' da veri setinden sıra ile alınan ham görüntüler gösterilmektedir. Şekil 11(b) ve Şekil 11(c)'de ise görüntüler üzerinde tespit edilen en büyük alana sahip iki nesne ayrı ayrı panellerde gösterilmektedir.

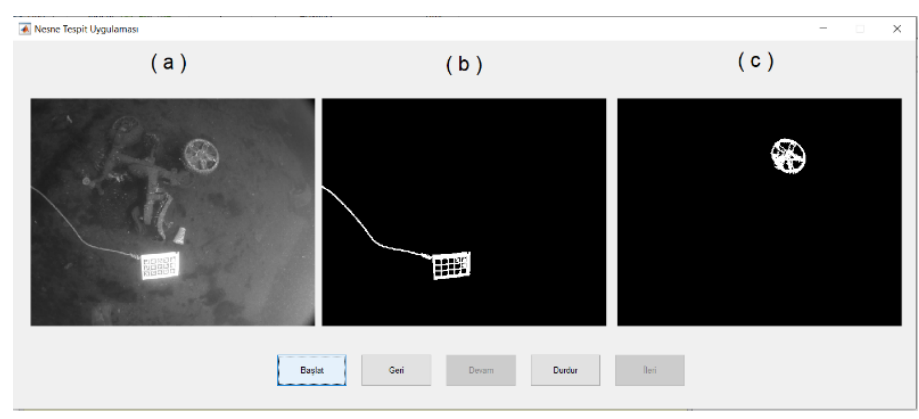

Şekil 11: Menu 2: Görüntüdeki tespit edilen nesneler

Geliştirilen uygulama Şekil 11(a)' da gösterilen ve özellikle deniz tabanına kalibrasyon için yerleştirilen nesne ve Şekil 11(b)'deki diğer nesne de dahil olmak üzere görüntüdeki deniz tabanından farklı bulunan nesneleri tespit edebilmiştir.

Sistem başarısını test etmek için veri setinden alınan ham görüntüler üzerindeki nesneler, insan gözü ile tespit edilerek etiketlendirilmiştir. Bu durum Şekil 12' de örnek bir görüntü üzerinde gösterilmiştir. Görüntü üzerinde etiketlendirme yapılırken deniz tabanından farklı görünen nesneler parça parça etiketlendirilmiştir.

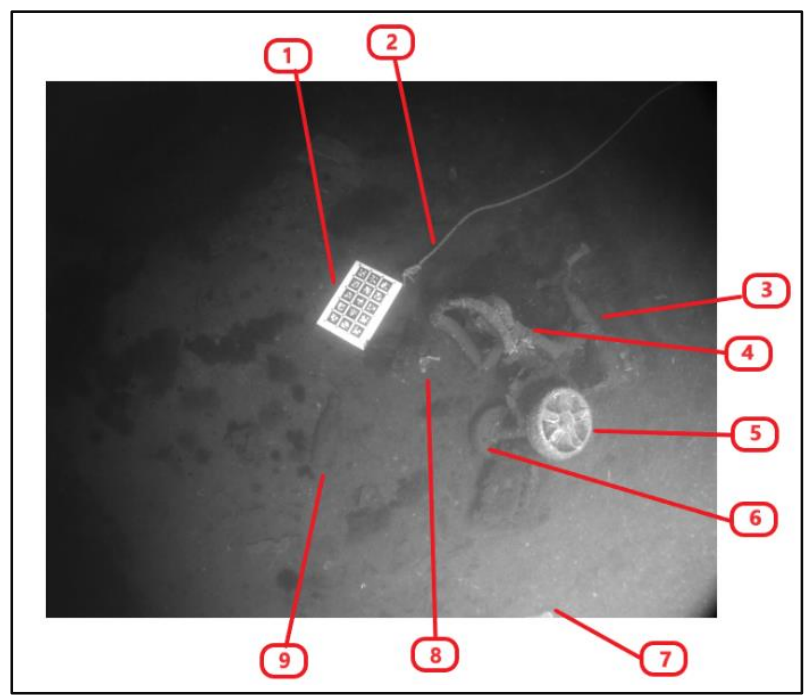

Şekil 12: Etiketlenmiş ham görüntü

Şekil 13'te uygulanan algoritma sonucu nesne tespiti yapılmış görüntü sunulmuştur. 


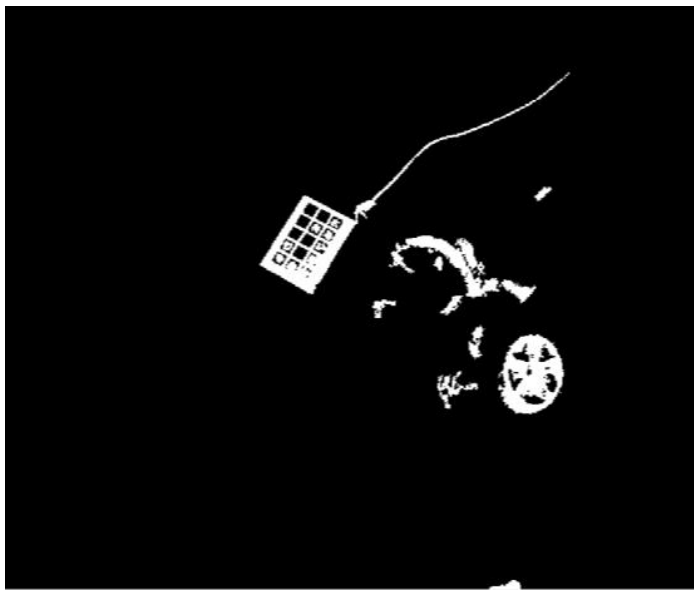

Şekil 13: Nesne tespiti yapılmış görüntü

Sistem başarısını ölçmek için veri setindeki her bir görüntü üzerinde etiketleme yapılarak elde edilen görüntüler ile nesne tespiti yapılan görüntüler karşılaştırılmıştır.

Karşılaştırma işlemi için Tablo’1 de gösterilen literatürdeki fonksiyonlar kullanılmıştır.

Tablo 1: Hata fonksiyonlarl

\begin{tabular}{ll}
\hline $\begin{array}{l}\text { Ortalama Karesel Hata } \\
\text { (Mean Squared Error) }\end{array}$ & $M S E=\frac{1}{n} \sum_{i=1}^{n}\left(g_{i-} y_{i}\right)^{2}$ \\
\hline $\begin{array}{l}\text { Kök Ortalama Karesel Hata } \\
\text { (Root Mean Squared Error) }\end{array}$ & $R M S E=\sqrt{\frac{1}{n} \sum_{i=1}^{n}\left(g_{i-} y_{i}\right)^{2}}$ \\
\hline $\begin{array}{l}\text { Ortalama Mutlak Hata } \\
\text { (Mean Absolute Error) }\end{array}$ & $M A E=\frac{1}{n} \sum_{i=1}^{n}\left|\left(g_{i-} y_{i}\right)\right|$ \\
\hline $\begin{array}{l}\text { Ortalama Mutlak Yüzdesel Hata } \\
\text { (Mean Absolute Percentage Error) }\end{array}$ & $M A P E=\frac{100}{n} \sum_{i=1}^{n}\left|\frac{\left(g_{i-} y_{i}\right)}{g_{i}}\right|$ \\
\hline
\end{tabular}

Çalışmada kullanılan veriler normalize edilerek kullanılmış olup tercih edilen hata fonksiyonları ve içerikleri Tablo 1'de sunulmuştur. Tablo 1' de gösterilen fonksiyonlarda n kullanılan veri setindeki görüntü sayısını, $g_{i}$ etiketlendirilmiş ham görüntüdeki nesne sayısını, $y_{i}$ kullanılan algoritma sonucu görüntüde tespit edilmiş nesne sayısını ifade etmektedir.

Çalışmada MSE, RMSE, MAE ve MAPE hata fonksiyonları için sırasıyla $0.08,0.09,0.28$ ve \%16 olarak elde edilmiştir.

\section{Sonuç}

Çalışmada deniz tabanında bulunan nesnelerin tespit edilmesi amaçlanmıştır. $\mathrm{Bu}$ amaç doğrultusunda geliştirilen algoritma ile AQUALOC veri setinde bulunan su alt1 görüntülerinden nesnelerin tespit edilmesini sağlayan bir uygulama geliştirilmiştir.

Görüntü işleme uygulamalarında görüntü elde etmek için kullanılan donanımların kapasiteleri, nesne tespitinde önemli bir rol oynamaktadır. Özelikle sualtı görüntülemede kullanılan kameraların yüksek maliyetli olması birçok sualtı araştırmasını da olumsuz etkilemektedir. Çalışmada bu durum göz önünde bulundurularak düşük kapasiteli donanıma sahip bir kameradan elde edilen görüntüler tercih edilmiştir.

Tercih edilen kamera ile alınan görüntüler incelendiğinde, deniz tabanındaki nesnelerin hazırlanan algoritma ile tespit edilebildiği Şekil 13 'te gösterilmiştir.

Hazırlanan yazılım ile minimum hata değerleri MSE, RMSE, MAE ve MAPE hata fonksiyonları için sırasıyla 0.08, $0.09,0.28$ ve $\% 16$ olarak elde edilmiştir.

Geliştirilen uygulama AQUALOC veri setindeki görüntüler üzerinde çalışmasına rağmen, gerçek zamanlı alınabilecek görüntüler üzerinde de uygulanabilir niteliktedir. $\mathrm{Bu}$ nedenle deniz tabanından geçirilen petrol boru hattı gibi enerji hatları ile diğer iletişim hatlarının güvenliklerini sağlamak amacıyla kullanılan insansız sualtı araçlarında da kullanılabilecek yapidadir.

Çalışmanın ana gayesi deniz tabanında bulunan farklı nesnelerin tespit edilmesi olmasına ragmen, ilerleyen dönemlerde çalışma geliştirilerek deniz tabanındaki nesnelerin sınıflandırılmasını da içererecek şekilde genişletilmesi planlanmaktadır. Çalışmanın şuan ki hali ile de sınırlı sayıda bulunan sualtı görüntüleri üzerinde nesne tespiti ile ilgili çalışmalara katkı sağlayacağı aşikardır.

\section{Kaynakça}

Au, W. W. L. (1993). The sonar of dolphins. Springer Science \& Business Media.

Çelebi, A. T., \& Ertürk, S. (2012). Visual enhancement of underwater images using Empirical Mode Decomposition. Expert Systems with Applications, 39(1),800-805. https://doi.org/10.1016/j.eswa.2011.07.077

Chen, Z., Zhang, Z., Dai, F., Bu, Y., \& Wang, H. (2017). Monocular vision-based underwater object detection. Sensors(Switzerland),17(8). https://doi.org/10.3390/s17081784

Ferrera, M., Creuze, V., Moras, J., \& Trouvé-Peloux, P. (2019). AQUALOC: An underwater dataset for visual-inertialpressure localization. The International Journal of Robotics Research,38(14),1549-1559.

https://doi.org/10.1177/0278364919883346

Han, F., Yao, J., Zhu, H., \& Wang, C. (2020). Marine Organism Detection and Classification from Underwater Vision Based on the Deep CNN Method. Mathematical Problems in Engineering, 2020. https://doi.org/10.1155/2020/3937580

Karimanzira, D., Renkewitz, H., Shea, D., \& Albiez, J. (2020). Object detection in sonar images. Electronics (Switzerland),9(7),1-16. https://doi.org/10.3390/ELECTRONICS9071180

Leblebicioğlu, M. K., Akar, G., Halıcı, U., Kartal, K. S., Saç, H., \& Shabanı, R. (2015). İnsansız sualtı araçları için yol planlama ve sualtı optik görüntülerin akustik görüntüleme desteği ile iyileştirilmesi.

Mukundan, R., \& Ramakrishnan, K. R. (1998). Moment functions in image analysis: theory and applications. World Scientific. 
Nur, S., Hamal, G., \& Ulvi, A. (2020). Türkiye Fotogrametri Dergisi Su A ltı Fotogrametri Yöntem i v e Kullanım Alanı Üzerine Bir Literatür Araştırması A Literature Study on Underwater Photogrammetry Method and Usage Area. 2(2), $60-71$.

Nyrkov, A. P., Zhilenkov, A. A., Korotkov, V. V, Sokolov, S. S., \& Chernyi, S. G. (2017). Development of underwater robotics. Journal of Physics: Conference Series, 803, 12108. https://doi.org/10.1088/1742-6596/803/1/012108

Solak, S., \& Altınışık, U. (2018). Görüntü İşleme Teknikleri ve Kümeleme Yöntemleri Kullanılarak Fındık Meyvesinin Tespit ve Sinıflandırılması. SAÜ Fen Bilimleri Enstitüsü Dergisi,February,1-1. https://doi.org/10.16984/saufenbilder.303850

Stanford Artificial Intelligence Laboratory et al. (2020). Bag Files. http://wiki.ros.org/Bags

Suzuki, S., \& be, K. (1985). Topological structural analysis of digitized binary images by border following. Computer Vision, Graphics, and Image Processing, 30(1),32-46. https://doi.org/10.1016/0734-189X(85)90016-7

Taşyapı Çelebi, A. (2012). Sualtı görüntülerinde iyileştirme ve hedef tespiti. Doktora Tezi, Kocaeli Universitesi, Fen Bilimleri Enstitusu, Kocaeli.

Van Den Boomgaard, R., \& Van Balen, R. (1992). Methods for fast morphological image transforms using bitmapped binary images. CVGIP: Graphical Models and Image Processing,54(3),252-258. https://doi.org/10.1016/10499652(92)90055-3

Williams, D. P., \& Groen, J. (2011). A fast physics-based, environmentally adaptive underwater object detection algorithm. OCEANS 2011 IEEE - Spain. https://doi.org/10.1109/Oceans-Spain.2011.6003424

Zhu, Y., Chang, L., Dai, J., Zheng, H., \& Zheng, B. (2016). Automatic object detection and segmentation from underwater images via saliency-based region merging. OCEANS 2016-Shanghai, 1-4. 